\title{
La amistad dialógica en tiempos recios
}

\author{
José Luis Ocasar Ariza \\ George Washington University \\ ocasarjl@gmail.com
}

Recepción: 13/03/2014, Aceptación: 05/05/2014, Publicación: 17/12/2014

\begin{abstract}
Resumen
El carácter crítico de los Coloquios de Palatino y Pinciano de Juan Arce de Otálora abarca casi todo el panorama cultural de mediados del siglo xvi. No obstante, la obra tiene un tono esencialmente jovial, que evita las usuales angustias de los heterodoxos. La clave de esta aparente ligereza es el sentimiento de la amistad que desde el primer momento impregna este coloquio y adquiere nueva importancia en el Renacimiento. La amistad no acontece solo entre los interlocutores, sino que tiene un papel esencial en la génesis de la obra. Asimismo, Otálora la extiende a todos los letrados, que formarían una comunidad invisible. Detrás de todo ello, aparecen ocultas las figuras de Erasmo y de Plutarco en una traducción encubierta.
\end{abstract}

Palabras clave

Arce de Otálora; Coloquios de Palatino y Pinciano; diálogo; amistad; humanismo; Plutarco; Erasmo; traducción

\begin{abstract}
The dialogical friendship in harsh times

The critical intention of Arce de Otálora's Coloquios de Palatino y Pinciano embraces the greater part of mid-XVIth century. Nevertheless, the work has an esentially joyfull tone, avoiding the usual anguish and despair of nonconformist or dissenting people. The key of this lightness is friendship, a feeling that arises from the very first lines of this dialogue and acquires new importance in the Renaissance. Friendship doesn't appear only between interlocutors, but is essential in the genesis of this work. Moreover, Otálora extends it to all the literates, who would take part of an invisible community. Behind this, the hidden figures of Erasmus and Plutarch emerge in an undercover translation.
\end{abstract}

\section{Keywords}

Arce de Otálora; Coloquios de Palatino y Pinciano; dialogue; friendship; Humanism; Plutarch; Erasmus; translation 
Se ha puesto de manifiesto repetidas veces que el valor de la amistad experimenta una nueva dimensión cultural en el Renacimiento ${ }^{1}$, especialmente con la aparición de la imprenta. A los tipos y modos tradicionales de lo amical se suma una nueva variedad, antes apenas documentada, y es la de aquellos amigos surgidos a raíz de la lectura. La rápida difusión de los impresos posibilita la aparición significativa de los amigos distantes, los nunca antes vistos, fabricados mediante la lectura en países lejanos. Esta relación privilegiada entre autor y lector había sido conocida por los clásicos, pero presuponía la distancia espaciotemporal entre emisor y receptor, que rara vez podía acceder al contacto personal; leyendo a los clásicos parece que podríamos encontrar en el autor muerto hace quizás centenares de años ese amigo al que se añora sin saberlo. Por la lentitud en la difusión de las obras antes del siglo xv, mediante la lectura se podía salvar el espacio, pero no el tiempo. Las obras clásicas de la sabiduría vienen de un tiempo que sitúa a sus autores fuera de nuestro espacio cronológico. Una de las implicaciones de la imprenta es precisamente la cercanía temporal entre los dos extremos del proceso comunicativo textual. Para entrar en contacto personal y directo con un autor admirado ya sólo habrá que salvar las diferencias espaciales. El viaje motivado por la admiración hacia un escritor y basado en sus textos se hace realidad. Anteriormente el arquetipo de dicho viaje se basaba en lo oral: la fama se transmitía por la palabra hablada. El trayecto para conocer a un sabio se originaba, pues, en una fama que volaba sobre la oralidad, al modo del amor de oidas, frecuente en otras literaturas, aunque no tanto en la española. ${ }^{2}$

La posibilidad de visitar a los grandes sabios europeos en vida era una de las consecuencias que ofrecía la masiva divulgación proporcionada por la imprenta. Este carácter extensivo de la edición se encuentra en la base de las nuevas redes de lectura masiva que van a proliferar durante el siglo xvi. Las Academias acabarán siendo su cara más visible y famosa, pero constituyen sólo una de las facetas de un movimiento más amplio, que incluye comentarios epistolares, tertulias y cenáculos y lo que podríamos denominar clubes internacionales de admiradores. Fue Robert Mandrou el que, en época reciente, rescató el término sodalitates

1. Por ejemplo, el «cult of friendship» que Kristeller adjudicaba al Renacimiento: «The friendship between scholars is one of the characteristic features of Renaissance humanism, and as so many other things, it is an inheritance from classical philosophy and literature where friendship appears a prominent topic of moral discussions in Plato, Aristotle, Epicurus, Cicero and others». (Kristeller 1980: 14). Para una panorámica sobre esta cuestión, vid. Hyatte (1994), especialmente el c. 1. Este trabajo forma parte del proyecto I+D del MICIIN, FFI2009-08070 y su continuación del MINECO FFI2012-33903.

2. La oralidad no sólo era el vehículo de la fama póstuma («Murió el onbre mas no murió el su nome» Conde Lucanor, ej. XVII), sino también su base, como se afirma en los Bocados de Oro: «...por que la sapiencia es cosa linpia e santa, non nos conviene de la poner si non en las almas vivas e non en los pellejos muertos. E por eso non fizo libros ningunos, nin lo que mostrava a sus discípulos, non ge lo mostrava por libro si non por palabra solamente» (cap. XI, «De los dichos y castigamientos de Sócrates, el Filósofo»). 
litterarum para designar a estos grupos que, reunidos bajo la figura de un magister, puntearon con sus actividades la vida cultural de la Europa del Quinientos. ${ }^{3}$ Lectores distantes y distintos unidos por textos que salvaban rápidamente las montańas y los mares fueron tejiendo una nueva madeja de relaciones.

Que la floración de diálogos y epístolas en el Renacimiento está relacionada con este nuevo impulso de la amistad no resulta sorprendente, como resalta J. F. Vallée $e^{4}$. Una sodalitia funcionaba de forma variablemente regular y sus contornos muchas veces eran imprecisos, pero su papel como predecesoras de las Academias del XVI-XVII se hace indiscutible a partir de la invención de la imprenta. Los participantes compartían su pasión por las letras, pero al mismo tiempo formaban un círculo de amistad que se acabó reflejando en la gran cantidad de literatura de elogios, recomendaciones y cartas que son imprescindibles para considerar la cultura del Quinientos. La afición común y la amistad impulsan un círculo de influencias en el que el poder del grupo se proyecta más allá de las reuniones, sesiones y tertulias, para traslucir en los prólogos, epístolas nuncupatorias, dedicatorias, poemas, cartas de recomendación y billetes varios que se difundieron a raíz de la imprenta y que con frecuencia resultaron una especie de feed-back de la misma. Si los libros viajaban por Europa, las visitas a Erasmo, Vives, Melanchthon, Budé y demás humanistas célebres iban precedidas de desarrollos epistolares o acompañadas de cartas de presentación de algún conocido. Las redes dejaban huellas textuales. Con esto se añade una dimensión más materialista a la consideración de la amistad, frecuentemente teñida de bellas palabras en su expresión y en su análisis, pero que funciona frecuentemente también en otro nivel de intercambio de favores. Aceptar dedicatorias, prologar libros, recomendar amigos o escribir poesías laudatorias son formas renacentistas de reciprocidad de la palabra.

El diálogo es susceptible de ser estudiado como una de las huellas textuales que las relaciones amistosas dejaron en la Europa del siglo xvi. No es casual que el género de los diálogos familiares, esto es, como conversación amistosa, en estilo medio, difundidos a partir de la obra erasmiana, sean la aportación principal del Renacimiento al género dialógico. Los debates medievales, con frecuencia entre adversarios u opuestos (el agua y el vino, el amor y el viejo, el cristiano y el judío, etc.) dejan paso en el Quinientos con frecuencia a conversaciones distendidas en las que la persuasión se produce en un ambiente favorable. En este punto es evidente la huella de Cicerón, cuya concepción del diálogo entre personajes históricos y virtuosos los sitúa en pie de igualdad. ${ }^{5}$ En Erasmo, por su

3. Robert Mandrou (1978: 56). No es que Mandrou hubiese acuñado el término, como sugiere Jean-François Vallée (2004: 54), pues sodalitia era ya en el siglo Xvi el predominante para denominar varias agrupaciones de letrados. Vid. Hankins, James (2009).

4. Si bien puntualiza: «However, the — perhaps too obvious — link between the written dialogue genre and the topos of friendship is still in need of study» (2004: 44-45).

5. "[Le dialogue] repose sur una humanité libre et généreuse, qui trouve à s'exprimer dans l'amitié. Crassus, Antoine, Scaevola, Cotta, Sulpicius, les interlocuteurs du De Oratore, sont très 
parte, incluso cuando los personajes encarnan valores opuestos, frecuentemente se deja claro que han sido antiguos amigos separados por el tiempo y las circunstancias (Miles et cartusianus) o que la experiencia de uno le hace comprender los errores del otro (Uxor mempsigamos): siempre hay una base para un componente amistoso de unión. En este sentido, la amistad funciona como un correlato o analogía textual del irenismo erasmiano que buscaba siempre la igualación, el entendimiento y el punto medio entre posturas ideológicas e incluso religiones.

Me propongo analizar cómo la amistad entendida como relación interpersonal y también como integrante del panorama del Renacimiento deja sus huellas en los Coloquios de Palatino y Pinciano de Juan Arce de Otálora, tanto en su texto como en su proceso genético. Y, presumiblemente, podremos concluir que en esto no resulta una excepción en el panorama europeo, sino más bien un síntoma de una presencia humana tan universal como sometida a los condicionamientos culturales y tan esencial como compleja.

\section{En camino desde el prólogo}

El diálogo arciano se abre con un prólogo muy trabajado, como demuestra el avant-texte que tenemos accesible en sus dos versiones ${ }^{6}$. Escrito primero (ms. Z) como un preliminar unitario, la segunda y definitiva redacción (ms. B) lo presenta dividido en dos partes. La primera mantiene sin alteraciones de importancia el texto de Z; sin embargo, la segunda parte del primitivo prólogo se presenta ahora bajo la forma de una "Carta enviada al autor por un grande amigo suyo", refacción que presenta cambios de interés, desde los necesarios ajustes sintácticos de una $1^{\mathrm{a}}$ a una $2^{\mathrm{a}}$ persona, hasta amplias consideraciones concernientes al género. En efecto, el desarrollo monolítico del primer prólogo se escinde aquí en esa suerte de diálogo diferido que es la epístola, cuyas relaciones con el coloquio han sido puestas de manifiesto muchas veces ${ }^{7}$. Es la amistad la matriz que deslinda los dos discursos, como un reflejo evidente del coloquio que va a seguir.

«Amigo» es palabra que aparece ya en las primeras líneas del prólogo, en el que Arce declara que buscar un amigo para enderezarle la obra es uso común, pero que él ha preferido dedicarla a «todos y cada uno» de los lectores, especial-

proches les uns des autres. Ils sont adultes, ont tous exercé dans l'Etat des charges très hautes qui permettent à la fois d'établir entre eux une hiérarchie et de les rapprocher fondamentalement par la dignité. Aucun ne peut prétendre imposer absolument à ses interlocuteurs una autorité magistrale. Ils sont donc réunis moins pour se donner mutuellement des préceptes (quoique certains jouïssent d'une supériorité reconnue) que pour chercher ensemble ou pour éprouver les uns sur les autres les leçons dont, au demeurant, ils se sentent comptables»; Alain Michel (1984:11).

6. Ocasar (2008). A partir de ahora, los números entre paréntesis remiten a las páginas de mi edición de los Coloquios (Ocasar: 1995).

7. Remitimos aquí a lo dicho en Ocasar (2008: 107 y ss.). 
mente a los universitarios salmantinos (3). El amigo receptor y protector de una obra se difunde aquí en una especie de amistad ampliada. ¿ ¿Se trata sólo de un artificio retórico? No lo parece: a diferencia del omnipresente modo irónico del autor, aquí late un tono de sinceridad, cierta ausencia de malicia. No se detectan dobles sentidos o reticencias cuando afirma que «entre los cuales [universitarios] siempre he reconocido a los principales y mayores por señores, y a los iguales de mi estado y condición por amigos y compañeros». Coincidiendo con algunas variantes genéticas analizadas, en las que Arce de Otálora se muestra conmovido al recordar sus años estudiantiles ${ }^{8}$, en este momento, que es el auténtico final genético de la obra - pues el prólogo siempre se escribe al terminar el texto-, cabe detectar un movimiento cordial expansivo. Al igual que el entero prólogo se desdobla en dos discursos, el narratario se disuelve en una colectividad de ideas a la que Arce se siente unido, en una especie de sodalitas ampliada. Esta estrategia difusora o difuminadora supone también una vía de escape del control de la palabra que implicaba el mecenazgo: con ella el autor (que social y económicamente se lo podía permitir) evitaba la posibilidad de quedar sometido a una única voluntad censora, la del mecenas, para otorgar a una audiencia ampliada la posibilidad de ejercer su control al margen del patrocinio de un prócer.

La división del texto preliminar para representar un intercambio epistolar amistoso y la dedicatoria a una comunidad de camaradas ideales no son, sin embargo, los únicos generadores textuales que proyecta la amistad en el prólogo. En efecto, Arce, siguiendo un tópico que no excluye la realización del hecho ${ }^{9}$, afirma que sus «borrados papeles» (con un calificativo que es huella de una autoconciencia crítica que las variantes genéticas han confirmado) fueron descubiertos por él a un amigo "verdadero y erudito», el cual le «importunó y cuasi forzó» a publicarlos. El amigo saca a la luz papeles que estaban destinados, si hemos de creer al jurista, al secreto y, en última instancia, a la pérdida. ¿Debemos identificar este amigo con el autor de la Carta? En nuestra opinión, claramente sí; Arce envía el diálogo a su amigo, el cual, como se dice, se entera de su existencia gracias al propio autor y le anima fervorosamente a su publicación. En su función de co-prologuista el amigo es presentado como «docto y muy curioso» (15) lo que semánticamente coincide con su primera presentación, cuando Arce le otorga «discreción y erudición» (8), para luego llamarle "otro Quintilio» (8), «verdadero» (8) y «escogido y leal» (9). Arce delimita así la figura ideal del amigo. Sus afinidades electivas («escogido») se encaminan claramente hacia la

8. En el ms. Z, Arce, hablando de los estudios universitarios, añade en el margen: «y entonces será dulce su memoria, especialmente si los contamos con salud y prosperidad, quia dulce est in prosperitate preteritorum laborem recordatio», texto que pasó a la versión definitiva (1995: 187).

9. Recordemos que Arce se destacó como viajero interesado en «antigüedades» por Castilla, León, Asturias, Cantabria y el País Vasco, como atestiguan Nicolás Antonio y Ambrosio de Morales; Ocasar (1996). 
phronesis docta, la unión de la curiosidad (que empuja a querer saber) y la discreción (que enseña a saber callar y a ser «leal»).

El prólogo aún delimita una segunda figura amical. El viaje que suscita y enmarca el diálogo entre Palatino y Pinciano tuvo lugar realmente, afirma Arce. Acaeció, según declara, «que, habiendo salido de Salamanca por principio de vacaciones con el más verdadero y escogido amigo y compañero de mi estudio con intención de holgarnos treinta o cuarenta días de las vacaciones, a la primera jornada, tratando de escoger una plática con que pudiésemos algunos ratos sin pesadumbre engańar el trabajo del camino, volviendo la cabeza a la ciudad que dejábamos atrás, comenzamos a contemplar...» (10). Una vez más, el amigo es «verdadero y escogido». Pero parece claro que este amigo de la juventud no tiene nada que ver con el corresponsal, pues en ningún momento quedan identificados como el mismo y el corresponsal habla de los personajes en tercera persona, sin sentirse vinculado con ninguno. La evidente figura alegórica de la vida como un camino nos hace ver que la escritura que nos propone Arce toma la forma de un recuerdo («volviendo la cabeza a la ciudad...»). Del mismo modo que Palatino y Pinciano miran atrás para repasar los sinsabores de la vida del estudiante, es una vez pasado el tiempo cuando Arce retoma el viaje que realizó con este otro amigo y vierte las pláticas habidas en él a lo escrito.

La crítica moderna tiende a dudar sobre la veracidad de este tipo de declaraciones, considerándolos tópicos veristas encaminados a otorgar calidad de vida a las creaciones literarias: una figura de evidentia, mero juego literario. No obstante, los estudios sobre usos sociales del Quinientos deberían incitarnos a reconsiderar nuestro escepticismo sobre muchas de estas figuras; más bien podríamos aceptar que algunos de estos pretendidos tópicos literarios responden a unos referentes reales. Ya hemos mencionado la fama de viajero curioso de Arce de Otálora; sabemos que, al estudiar en Salamanca y residir en Valladolid, debió de realizar el trayecto entre ambas ciudades a menudo y que siempre era preferible viajar acompañado. Los estudios sobre la conversación como práctica social aportan mucha luz a la comprensión de estas presentaciones constantes en el género. ${ }^{10}$

Este amigo con el que Arce afirma haber viajado — y que sería encarnado por Palatino, como ya aventuramos desde un principio-, no solamente cumple la función de acompañante e interlocutor, es decir, como presencia en el coloquio, sino que además desempeña otra de tipo performativo. En efecto, el amigo y com-

10. Véanse Strosetzki (1984), Burke (1993), Goldsmith (1988), Fumaroli (1994), Godo (2003). Las referencias de Pedro de Navarra a la poco documentada academia de Jorge de Armagnac; la mención de un cenáculo o sodalitas en la Ingeniosa comparación entre lo antiguo y lo presente, de Cristóbal de Villalón; las de Pedro Mexía a las charlas en las gradas de la Catedral de Sevilla, las cenas de los Diálogos de apacible entretenimiento de Gaspar Lucas Hidalgo, etc. se aceptan de forma regular como referencias correspondientes a usos sociales existentes (lo que no significa negarles valor literario o simbólico). Evidentemente, no lo son otros de probada tradición literaria o bien de carácter fantástico o inexistente, como los diferentes diálogos infernales, entre personajes mitológicos o entre animales. 
pañero, «me decía algunas veces que sería justo, por que del todo no se perdiese esta recordación, se hiciese una sumaria escriptura y probanza della, ad perpetuam rei memoriam». Es decir, el amigo viajero induce y anima a la escritura del mismo modo en que el otro amigo interviene y motiva la publicación. Y paralelamente, si el que incita a la publicación «vino a saber de mí este secreto» y contribuyó a su difusión, Arce escribe los Coloquios «a su [del compañero de viaje] instancia, sin que él ni otra persona lo entendiese y barruntase», es decir, en secreto.

La escritura arciana, pues, nace con carácter secreto y en un contexto de amistad, de la que toma su forma literaria (coloquio) y su posibilidad de existencia. Ambos amigos conforman una especie de arquetipo extraído del quehacer profesional (de las cinco veces que aparece la palabra compañero en el prólogo, cuatro lo hace siguiendo a amigo), que comparte con el autor curiosidad y deseo de saber y que está capacitado por la "ley de amistad» para animar e intervenir en la actividad textual. Volveremos a este punto.

El Arce literario, narrador y personaje, aparece siempre flanqueado por la figura del amigo. Arce viaja con un «amigo y compañero» y tiene a todos los universitarios salmantinos por «amigos y compañeros». Esta expansión amistosa configura un receptor / protector ilustrado, una comunidad de ideas que agavilla a los letrados. Y es a ellos a los que se dirige Arce, recordando «lo que decía Tulio en el libro De Amititia, que si subiera al cielo y viera las maravillas de allá y la gloria de los dioses, no gozara de contentamiento si no tuviera a quien comunicar lo que había visto ${ }^{11}$ » (9). La cita del texto básico de la literatura clásica sobre la amistad en un contexto prologal confirma esta orientación amistosa que tińe la obra en su conjunto.

No obstante, Arce ya ha mencionado en dos ocasiones lo que de pasatiempo tienen los Coloquios, escritos a ratos perdidos, sin que nadie lo supiese y sin una decidida voluntad de publicación. La orientación inicial de la obra hacia el secreto y el silencio es torcida por la intervención de los amigos, que intervienen en el devenir de la escritura. No obstante, el secreto subsiste todavía en la precaución que muestra el autor al sugerir dos niveles de lectura: Arce pondría su obra en la plaza pública para que todos pudieran enmendarla, en otra imagen de humildad política; pero, repitiendo un viejo adagio, preferiría hacer dos: una excelente y dirigida a los sabios y otra popular y encaminada "para contentamiento del vulgo» (12). Es decir, por un lado la dedicatoria a la comunidad de los letrados esquiva la censura previa del mecenas; por otro lado, el establecimiento de una "fermosa cobertura» que asegure un nivel de entretenimiento popular y otro de entendimiento esotérico para los pocos, supone otra línea de defensa de la obra, que es susceptible de acogerse en cada momento a la clave hermenéutica que garantice su supervivencia.

11. Cicerón, De amicitia, 88. 


\section{La réplica de la amistad: la Carta}

El análisis de la carta en respuesta al prólogo forzosamente ha de ser menos demorado. La conservación del avant-texte nos permite conocer (por si hubiera alguna duda) el carácter decididamente ficticio de este amigo, que hace suyas las palabras que el autor se había autoasignado en la primera redacción. En efecto, la parte del prólogo que la carta viene a sustituir es abiertamente apologética: Arce escribe en el manuscrito $\mathrm{Z}$ y luego tacha: «Una cosa no dexare de hazer, que sera bolver por mi honrra en apuntar algunos avisos que en esta obra se guardaron, por que si nadie dixere bien della no me quede lastima de no la aver alabado y estimado para casarla, que las tachas no faltara quien las diga». Y da en el margen instrucciones precisas: «todo quanto se sigue se ha de dexar hasta los diez renglones postreros del prologo do dize plega a dios etc y acabado el prologo poner la carta de que esta añadida» ${ }^{12}$.

Nos encontramos aquí con un movimiento en parte común a gran cantidad de textos dialógicos: la escisión del discurso del autor en dos instancias conversacionales. Lo que primero fue redactado como parte del discurso autorial ahora corre a cargo de un yo ficcionalizado. Siguiendo el carácter fuertemente dialógico que Erasmo otorgaba a sus cartas (en la tradición de otros escritores clásicos y de la patrística) $)^{13}$, la epístola del "grande amigo» está escrita en un tono íntimo, desenfadado y llano, connotando una amistad sólida.

¿En qué circunstancias coloca Arce de Otálora a este amigo ideal, digno receptor y juez de su escondida obra? Frente al carácter secreto que desde el principio el autor ha establecido para la elaboración de los Coloquios, el amigo los recibe retirado en una aldea, «tan privado de toda buena compañía y conversación, que es la cosa de esta vida que a mí más me enfada entre todas cuantas el aldea tiene» (15). La sociabilidad aparece como el primer rasgo del receptor invitado a ser juez de la obra, pues se siente a disgusto aislado de la sociedad. En esto cabe leer un cierto contraste con el aislamiento dinámico en el que Palatino y Pinciano van a desarrollar sus coloquios: el amigo está des-plazado en el silencio, excluido de la conversación, mientras que ese silencio ambiental es condición necesaria para que los amigos hablen. Silencio y diálogo se sitúan para Arce en relación dialéctica, como opuestos que se complementan: sin el primero no se puede dar el segundo y este aparece destinado al primero. Entre ambos, el amigo que saca la palabra del silencio en la conversación y, una vez fijada, la rescata también del secreto.

También en contraste con lo escrito en primera instancia, esto es, que Arce mismo iba a elogiar su propia obra, el amigo dice que habrá de despojarse «de la

12. El material genético referido a ambas redacciones se encuentra en el CD que acompaña a Ocasar (2008) y analizado sobre todo en las páginas 107-111 del texto.

13. Est enim [quod scite scriptum est a Turpilio comico] epistola absentium amicorum quasi mutuus sermo. Erasmo, De conscribendis epistolis. Vid Lisa Jardine (1993: 150). 
persona de amigo para hacer bien la de juez» (15). Es decir, aunque subsiste la intención panegírica, ahora se afirma que se va a ser objetivo e imparcial. Es uno más de los birlibirloques intencionales de la obra, susceptible de ser leída en varias capas de propósitos diversos y de sucesivos engaños. Geminado por un espejo que lo desmiente, el autor mantiene sus palabras iniciales, si bien oculta su intención. La alabanza se disfraza de imparcialidad e incluso de enemistad: «y vestirme de un ánimo como contrario y achacoso» (15).

El amigo confirma algo que ya había sido posible entreleer en la primera parte del prólogo: dice haber leído el libro «no sólo una vez, sino muchas y con grande atención y intención de no perdonar ni dejar pasar por alto ni bajo cosa alguna, por liviana que pareciese (que grande y notable ninguna hallé). Lo que me pareció se podía quitar y mudar, en un cuadernillo lo envío apuntado de un pliego de papel» (15-16). Una vez más, la amistad deja huellas textuales; el amigo es quien puede reelaborar el discurso. ${ }^{14}$ Es difícil no ver en esto una verdadera e involuntaria metáfora del diálogo (de un cierto tipo de diálogo, al menos): la variación de nuestro ser producida por una influencia amistosa ${ }^{15}$.

Esta intervención en lo escrito tiene un correlato real en la propia génesis de los Coloquios: cuando analizamos el proceso de creación ya hablamos de lo que parecía ser una «composición sindicada» que diluye la idea de autor único ${ }^{16}$. Otras personas que no son Arce intervinieron en la redacción, en los «borrados papeles». El amigo envía a Arce sus observaciones en un pliego de papel, es decir, en 4 ó 8 páginas, una vez doblado (aunque podrían ser más, dependiendo de los dobleces). Una vez más, encontramos que los lazos aparentemente invisibles entre la vida social y la escritura se desvelan en el avant-texte; con razón ha podido decir Almuth Grésillon que la cuestión de los autores múltiples es una de las fronteras de la genética textual ${ }^{17}$. Es mucho aún lo que no sabemos de las prácticas de escritura de los tiempos anteriores a la edad de oro del material genético, es decir, los siglos XIX y XX, y por tanto mucho el campo que queda por investigar acerca de cómo determinadas obras se vieron afectadas por la intervención de amigos y albaceas, desde Virgilio hasta Kafka, desde Pérez de Oliva hasta Nietzsche, desde Garcilaso hasta Lovecraft.

14. Me señala Ana Vian, a quien agradezco mucho sus observaciones, el juego similar que se establece entre Sancho de Muñón y su supuesto amigo en los paratextos de la Tragicomedia de Lisandro y Roselia. En efecto, existen ciertos paralelismos entre ambas obras respecto a la intervención que un amigo, real o fingido, se permite en el proceso de creación; es decir, existe una clara voluntad en algunos escritores de interponer una instancia que aleje, relativice o atenúe la responsabilidad o la voz del autor.

15. Ya J-F. Vallée, citando a C. Demure, había visto que los personajes de la Utopía de Moro «are the very incarnation of the essential relation that holds humanitas together at its highest level: friendship" (2004: 49).

16. Ocasar (2008: 47).

17. Grésillon (2007: 35). 


\section{Amicitia como tema}

"Cuánto trabajo sea verter de una lengua en otra, y especialmente abriendo camino de nuevo y vertiendo cosas que hasta hoy en nuestra lengua no han sido vistas ni entendidas, cualquier justo y prudente lector puede conocerlo. Porque el que vierte ha de transformar en sí el ánimo y sentencia del autor que vierte, y decirla en la lengua que vierte como de suyo, sin que quede rastro de la lengua peregrina en que fue primero escrito, lo cual, cuán dificultoso sea de hacer, la tanta variedad de traslaciones que hay lo muestran claramente.» ${ }^{18}$

La amistad es, claro, también una materia debatible en una obra tan miscelánea como los Coloquios de Palatino y Pinciano, escritos con voluntad totalizadora. Desde el principio, Arce contrapone ventajosamente su obra a la Silva de Varia Lección de Pero Mexía, que había obtenido un gran éxito. La mayor diferencia entre ambos textos enciclopédicos no es, como Arce quiere al compararlas, la simple afirmación de que «la materia desta obra es la más universal de cuantos libros yo he visto» (22). Se trata más bien de ensartar las enseñanzas en una narración unitaria, en una cornice dinámica establecida a través de un coloquio amistoso. La experiencia vivida de dos amigos en un contexto familiar y realista nos permite asomarnos a la totalidad del conocimiento humano, presente y pasado. Un desayuno cotidiano, por ejemplo, nos pone en relación con la naturaleza y propiedades de los alimentos, con las historias y leyendas acerca de la comida, con el simbolismo de los comienzos y de la gastronomía. En cada pequeño acto rutinario asoma la cultura, pero no la cultura de un momento determinado en un paraje local, sino la entera historia del devenir cultural, la comparación, valoración y evolución de los usos humanos.

Palatino es, como ha quedado dicho, el amigo «verdadero y escogido» con el que viaja Pinciano (el Arce nominal, el portador del principatus, aunque comparta con su compañero la representación autorial). No obstante, como corresponde al carácter realista, ambiguo e irónico de su coloquio, su amistad está lejos de representar el concepto aristotélico-ciceroniano de la amicitia perfecta. Su relación, trufada de pullas y bromas, no está escasa de momentos poco virtuosos y elevados, aunque siempre veristas: el enojo de Palatino con su amigo al llegar a Villalar y perder su espada (jornadas IV-V), que incluye amenazas físicas, o sus malos pensamientos, decididamente poco amistosos (927); la irritación de Pinciano ante los tronchantes comentarios de Palatino respecto al linaje de los habitantes de Simancas (VII, 1) o su enfado ante una separación momentánea (923); la afirmación de Palatino de que mataría a Pinciano por haberle despertado (871); la amenaza de este de llevar a su amigo ante la Inquisición por agorero (932); los insultos, alusiones y motes que se

18. Pedro Simón Abril, Prólogo del intérprete al lector, de los Libros morales de Aristóteles, citado por J. Rubiera (2009), pg. 22. 
intercambian, entre otros, de necio (1134), malicioso (31 y 1391), etc. Todo ello contribuye a presentar una amistad apegada a lo real, ajena a las idealizaciones que abundan en tanta recreación del amigo perfecto. Los comportamientos y libertades de los interlocutores están alejados de la idea de virtud que informa los textos morales, pero en ellos reconocemos los latidos de la vida como es, no como debería ser.

La amistad como thema ocupa las estancias 2 a 5 de la jornada decimasexta. Estructuralmente, por lo tanto, se sitúa en un punto culminante de la obra. Las dos cuestiones que ocupan el resto de la jornada y la siguiente son la muerte (reforzando la identificación camino/vida) y una palinodia acerca de la tesis que se quería probar, esto es, la miseria de las letras; además, como un cierre abierto, se contará la historia de los dos estudiantes y las dos moriscas. Esta novella, que cierra la obra con una serie de interrogantes a los que no se da respuesta, simboliza el carácter abierto de la existencia, la posibilidad infinita y virtualmente inacabable de la palabra para seguir colonizando la realidad. Esta jornada decimoséptima es, pues, un cierre más metaliterario, que tiene que ver con el sistema seguido por Arce de Otálora para la redacción de sus Coloquios: ironía, diégesis y apertura del significado ${ }^{19}$.

La amistad, por consiguiente, es la última materia debatible antes de la muerte, y su introducción viene justificada precisamente por este carácter terminal. Palatino desea que Pinciano continúe hablando: «quisiera que no se acabara el camino ni la materia por gozar más de vuestra buena conversación, porque cierto me he holgado estrańamente en oíros» (1267-8). En el camino de la vida, pues, la conversación amistosa aleja la idea de la muerte, que de cualquier modo es inevitable. Y retomando una vieja idea de Cicerón ${ }^{20}$, afirma: «Y verdaderamente yo entiendo que una de las cosas que en esta vida se puede gozar es la compañía y conversación de un buen amigo y virtuoso como vos» (1268). Pinciano le corresponde con palabras similares, pero la conversación da un giro cuando Pinciano achaca a su amigo una cierta actitud lisonjera: «La aplicación tengo por algo sospechosa, por oler a lisonja, que es la que en ninguna manera, para conmigo ni para con otro, yo no querría ver en vuestra boca ni en vuestra condición ni de ninguno que bien quisiese, porque es la cosa más contraria de todas a la verdadera amistad y la que más la estraga y corrompe» (1268).

Durante las páginas siguientes, Pinciano, a requerimiento de su compañero, va a elaborar un discurso acerca de la distinción entre un amigo y un lisonjero. Es decir, el texto se separa de la esperable y conocida fuente ciceroniana ${ }^{21}$ para adentrarse en un

19. La enorme conciencia estructural de los Coloquios muestra un ejemplo claro cuando, en la jornada $13^{\circ}$, al conversar sobre la prudencia, Pinciano afirma: «Si no fuera por meterme en seso, yo me alargara en este artículo, y aun os mostrara a conocer el amigo del lisonjero, para que estimárades el uno y os guardáredes del otro. Pero no quiero agora miscere seria jocis. Podrá ser que se ofrezca ocasión, antes que lleguemos a Salamanca, para ello» (1049). Esto confirma que, lejos de ser un mero cosido de versiones, traducciones o noticias diversas, una decidida voluntad estructural alienta en toda la obra.

20. De amicitia, 20-24.

21. Esperable porque es muy citada por Arce. En realidad, sería imposible para un humanista del 
punto más concreto y, podríamos decir, colateral o subalterno. La transición desde el soslayado thema de la amistad a su distinción de la lisonja es suave y propia de una conversación que fluye naturalmente entre asuntos conexos. Pero Arce se ejercita aquí para ejercitar la labor por la que ha merecido el calificativo de humanista y vierte de forma encubierta un pequeño opúsculo clásico. La fuente es, sin duda, el De discrimine adulatoris et amici de Erasmo ${ }^{22}$, el primero de su Ex Plutarcho verba; Arce hace una fiel traducción de la mayoría de la obra, omitiendo alguna de sus partes.

Plutarco fue autor predilecto de Erasmo: en sus Adagia es el tercer autor más citado, sólo por debajo de Cicerón y de Homero ${ }^{23}$. En alguna ocasión lo calificó como sanctius y en sus dedicatorias de los Apophthegmata (Lyon, 1531) a Guillermo de Clèves y de la Institutio principis Christiani (Basilea, 1516) al príncipe Carlos, recomienda la lectura de la obra plutarquea. Y, por supuesto, Erasmo tradujo los Moralia, en los cuales Arce se basó para su versión al castellano. Se suma así el vallisoletano a la nómina de traductores españoles de Plutarco desde Fernández de Heredia a fines del siglo XIV.

Centrándonos en los Moralia (pues muchas de las traducciones son de las $V_{i d a s^{24}}$, antes de que Arce vertiera este tratadito habían aparecido las versiones de Diego Gracián (1548) ${ }^{25}$ y las parciales de Diego de Astudillo (1551) y una anónima de $1538^{26}$. De ellas sólo la versión de Gracián presenta el De discriminis.

El texto de Plutarco es el principal de sus escritos acerca de la amistad y está dividido en dos partes; en la primera compara el adulador con el amigo, mientras que en la segunda trata muy penetrantemente sobre el uso de la franqueza como un arma por parte del adulador. El lisonjero se amolda al adulado y adopta los usos del camaleón; halaga al hombre, en tanto el amigo alaba la acción. Y especialmente, el lisonjero imita la franqueza mediante la crítica suave de aspectos baladíes y poco importantes; la crítica del amigo duele, pero purifica. El adulador aconseja a nuestra parte irracional y busca ganarse nuestra confianza, mientras el amigo verdadero sólo pretende nuestro bien. Para encajar las críticas, debemos abandonar la arrogancia ${ }^{27}$.

siglo XVI escribir sobre el tema de la amistad sin recurrir a las fuentes clásicas; vid. P. Henry (1987: 96). Desde la Ética a Nicómaco a las epístolas de Epicuro a Idomeneo, Séneca a Lucilio o Cicerón a Ático, la amistad, la separación o muerte de los amigos, las leyes que la gobiernan, etc. son cuestiones con amplia tradición.

22. Cotejo con el cuarto volumen de la Opera omnia (Basilea, Froben, 1540), en el que el De discrimine se extiende entre las páginas 5 a 25.

23. Chomarat (1984:404).

24. Morales (2000: 88), a quien sigo en este punto.

25. Morales de Plutarco, traduzidos de lengua griega en castellana (Alcalá de Henares, Juan de Brócar, 1548). Hay una versión ampliada, Morales de Plutarco, traduzidos de lengua griega en castellana por el secretario Diego Gracián, criado de su Majestad. Va de nuevo añadida la quarta parte, que nunca ha sido impressa (Salamanca, Alexandro de Canova, 1571).

26. El primero tradujo el De cohibienda ira y Praecepta coningalia, y la anónima, aparecida en Valladolid, es del De cupiditate divitiarum. Contamos además con otras que quedaron manuscritas, obras de Páez de Castro y de Fernández de Villegas; Morales (2000: 89-91).

27. Míguez (2005:189). 
Arce, lejos de traducir servilmente el texto, lo manipula en varios sentidos. En primer lugar, evidentemente, trasvasa los contenidos del tratado al género dialógico. Para ello intercala en la amplia exposición de Pinciano los comentarios y reformulaciones de Palatino. Cabe interpretar sus intervenciones no solamente como un trámite para dar vivacidad o variedad al discurso de Pinciano, sino también como la expresión de una respuesta de Arce muchas veces intuitiva a lo narrado: «Esa fue algo agra respuesta, y demasiada libertad para con un príncipe» (1284), "A mal le salió a ése tanta amistad» (1286). Son breves comentarios cuya simplicidad es a la vez caracterización de un interlocutor menos sofisticado y expresión inmediata de sentimientos ante algún hecho o anécdota. Del mismo modo, no duda Arce en complementar el texto con aportaciones contemporáneas o su propia erudición. ${ }^{28}$

En segundo lugar, Arce altera la estructura del texto plutarqueo, pues su versión tiende a suprimir ejemplos redundantes, a seleccionar pasajes y a variar la estructura de la obra y la dispositio de muchos argumentos. En todo ello no se aparta del uso habitual de los humanistas al traducir a clásicos o a contemporáneos. Finalmente, cuando esmalta el texto castellano con fragmentos latinos, éstos sufren a su vez algún cambio, bien debido a malas lecturas (posiblemente a un copista que no supiese latín), bien a ajustes gramaticales para fusionar ambos textos. ${ }^{29}$

¿Conoció Arce de Otálora la versión anterior de Diego Gracián? Aunque no es descartable que el atento lector que era el oidor tuviese noticia de la traducción de su coetáneo, no existen rastros de influencia. De hecho, la práctica traductoria de uno y de otro es diametralmente distinta, lo cual no es extraño debido a la diferente naturaleza de sus versiones. Gracián, según afirma, traduce directamente del griego ${ }^{30}$ y se atiene a la letra, frente a la libertad con el texto que practica Arce, por lo que su versión es más extensa y elongada. Veamos un ejemplo concreto del tratamiento que se hace del texto de Plutarco/Erasmo por ambos autores:

28. Son añadidos por Arce ejemplos como: «y en Portugal dicen que azotaron un castellano porque decía mal de Lisboa» (1286) o «Hacen como el parásito terentiano: Si laudant laudo, si rident rideo» (1292) o el texto de Ovidio de la página 1290. También la alusión a Eurípides de la página 1282, que no aparece en Plutarco y que remite, sin anotarlo, al Orestes, 450, 802s, 1095 y ss. Vid. Jiménez (2001: 261). 29. En general las transformaciones del latín son bastante numerosas y arduas de interpretar. No obstante, a veces no es difícil discernir el motivo último de los cambios. Cuando Erasmo escribe: "Non est tibi, inquit, o bone, tibi negocium de reduuia", Arce transcribe: «Non est tibi, bone vir, negotium de unguium vitio"; ciertamente, reduvia y unguis vitio pueden ser considerados sinónimos, si bien el primer sustantivo es inaccesible a muchos lectores: las aptitudes de nuestro autor como latinista se muestran a la altura de su consciencia de las características de sus receptores ideales.

30. "He traducido estos Morales del original Griego, siguiendo en todo sin me desviar de la letra dél, correspondiendo prosa a prosa; y los versos de poetas que alega Plutarco, así mismo los he devuelto en metro y rima castellana, a exemplo de los otros intérpretes que con diligencia han traducido algo del griego en latín o en cualquier otra lengua vulgar, no me apartando punto del sentido literal Griego». Y posteriormente agrega algo que atañe a la labor de Arce de Otálora: «Que de otra manera, sacando del latín, es imposible acertar. Y por esto se verá claramente que no pueden dejar de errar los que por no entender la lengua griega han traducido en cualquier lengua vulgar de la translación latina sacada del griego» (Prólogo, s.p.). 


\begin{tabular}{|c|c|c|}
\hline $\begin{array}{l}\text { Erasmo, De discrimine } \\
\text { adulatoris et amico, Opera } \\
\text { omnia (1540), pg. 13-14 }\end{array}$ & $\begin{array}{l}\text { Diego Gracián, De saber cómo } \\
\text { podrá alguno determinar y } \\
\text { diferenciar el amigo del lisonjero } \\
(1548) \mathrm{f} .134 \mathrm{r}\end{array}$ & $\begin{array}{l}\text { Arce de Otálora, } \\
\text { Coloquios, pg. } 1274\end{array}$ \\
\hline $\begin{array}{l}\text { Quin etiam sunt et his } \\
\text { astutiores nonnulli, qui ipsa } \\
\text { reprehendendi libertate, } \\
\text { ad gratiam et voluptatem } \\
\text { utuntur. Quemadmodum } \\
\text { Agis Argivus, quum } \\
\text { Alexander ridiculo cuidam } \\
\text { ingentia daret munera, prae } \\
\text { invidia ac dolore exclamavit, } \\
\text { O rem vehementer } \\
\text { absurdam. Ac postquam } \\
\text { Alexander ira percitus } \\
\text { conversus ad illum dixisset, } \\
\text { \& quid tu tandem ais. Fateor, } \\
\text { inquit, me moleste ferre } \\
\text { \& indignari quum videam } \\
\text { omnes ex Iove prognatos, } \\
\text { aeque adulatoribus \& } \\
\text { ridiculis hominibus delectari. } \\
\text { Siquidem \& Hercules } \\
\text { Cercopibus quibusdam, \& } \\
\text { Bacchus Silenis delectabatur, } \\
\text { et apud te videre licet, } \\
\text { huiusmodi magni fieri. Porro } \\
\text { quum aliquando Tiberius } \\
\text { Caesar in senatum venisset, } \\
\text { surgens adulator quidam, } \\
\text { ait hominibus liberis libere } \\
\text { loquendum esse, nihilque } \\
\text { metu dissimulandum, neque } \\
\text { quiquem reticendum eorum } \\
\text { que ad publicam utilitatem } \\
\text { pertinerent. His verbis } \\
\text { quum omnes excitasset, } \\
\text { factoque silentio, \& ipso } \\
\text { etiam auscultante Tiberio, } \\
\text { Audi Caesar, inquit, in quo } \\
\text { te quidem culpamus omnes, } \\
\text { etiam si nemo palam audet } \\
\text { dicere. Negligis teipsum, } \\
\text { corpusque tuum exponis pro } \\
\text { nobis, sollicitudinibus \& } \\
\text { laboribus illud conficiens, nec } \\
\text { interdiu nec noctu quiscens. } \\
\text { Huiusmodi multa quum } \\
\text { ille dixisset, aiunt oratiorem } \\
\text { Cassium Severum subiecisse, } \\
\text { ista libertas hunc hominem } \\
\text { exitio dabit. }\end{array}$ & $\begin{array}{l}\text { Hay otros algunos destos más } \\
\text { astutos, que desta libertad de hablar } \\
\text { y reprehender usan por gracia y } \\
\text { para deleitar, como fue Agis el } \\
\text { Argivo, que viendo a Alexandre } \\
\text { dar a un truhan que le movía a risa } \\
\text { muy grandes dádivas, de envidia y } \\
\text { pesar dio voces diciendo: «jOh, qué } \\
\text { cosa tan mal hecha y tan afeada!» } \\
\text { A lo cual, como el rey tornase con } \\
\text { ira diciendo: «¿Qué es lo que tú } \\
\text { dices?», respondió: «Yo confiese } \\
\text { que me pesa y me ensaño viéndoos } \\
\text { a todos vosotros, los que venís } \\
\text { de casta de los dioses, holgaros } \\
\text { semejantemente con lisonjeros } \\
\text { y hombres truhanes, porque } \\
\text { Hércules dice[n] se deleitaba } \\
\text { con los Cércopes (que eran dos } \\
\text { hermanos Efesoas que pensaron } \\
\text { por engańo acometer a Hércules, el } \\
\text { cual los prendió y ató y después los } \\
\text { soltó y se holgó mucho con ellos) } \\
\text { y Baco con los silenos y juglares.* } \\
\text { Y cerca de ti vemos que éstos son } \\
\text { muy estimados». Viniendo una vez } \\
\text { Tiberio César al Senado, levantóse } \\
\text { en pie uno de los lisonjeros, } \\
\text { diciendo que a los hombres libres } \\
\text { les era dado hablar libremente y } \\
\text { no disimular ni callar ninguna } \\
\text { cosa de las que convenían al bien } \\
\text { de la república. Pues como todos } \\
\text { estuviesen atentos y le prestasen } \\
\text { atención y también el mismo } \\
\text { Tiberio le oyese y escuchase, dijo: } \\
\text { «Oye, César, en lo que todos te } \\
\text { culpamos, aunque ninguno osa } \\
\text { decir públicamente, es que no curas } \\
\text { de tu persona. Pones tu cuerpo a } \\
\text { peligro, aprémiasle y fatígasle con } \\
\text { ciudados y trabajos, por amor de } \\
\text { nosotros, no descansando de noche } \\
\text { ni de día». Después que hubo } \\
\text { razonado mucho desta manera, } \\
\text { dicen que habló Severo Craso, } \\
\text { orador, y dijo: «Esta libertad será la } \\
\text { causa de la destrucción y muerte de } \\
\text { este hombre». }\end{array}$ & $\begin{array}{l}\text { Y acaece ser tan primos } \\
\text { algunos oficiales deste } \\
\text { oficio que en la misma } \\
\text { reprehensión llevan la } \\
\text { lisonja, como cuentan } \\
\text { de Agio Argivo, que, } \\
\text { habiendo dado Alejandro } \\
\text { un gran don y merced } \\
\text { a un su competidor del } \\
\text { mismo oficio, dio una } \\
\text { voz grande, diciendo: } \\
\text { "O, rem vehementer } \\
\text { absurdam!»; y volviéndose } \\
\text { a él Alejandro, enojado, } \\
\text { le preguntó por qué } \\
\text { había dicho aquello, y } \\
\text { él respondió: «Fateor } \\
\text { me moleste ferre quod } \\
\text { videam omnes Jove natos } \\
\text { adulatoribus delectari, } \\
\text { siquidem Hercules } \\
\text { Cecropibus quibusdam et } \\
\text { Bacchus Silenis deletabatur } \\
\text { et apud te idem videre } \\
\text { tamem». } \\
\text { PALATINO.- } \\
\text { Agudamente encajaba } \\
\text { la saya. } \\
\text { PINCIANO.-Más } \\
\text { delicadamente encajó } \\
\text { otro que, estando Tiberio } \\
\text { César en el Senado, se } \\
\text { levantó y dijo en voz } \\
\text { alta: «Los hombres } \\
\text { libremente han de hablar } \\
\text { en lo que toca a su rey } \\
\text { y a su república. Audi, } \\
\text { Cesar, in quo te culpamus } \\
\text { omnes, etiam si nemo } \\
\text { palam dicere audeat: } \\
\text { negligis te ipsum corpusque } \\
\text { tuum exponis pro nobis } \\
\text { solicitudinibus et laboribus } \\
\text { nec inter diu nec in nocte } \\
\text { quiescens»; y esto, muy } \\
\text { encarecido. Casio Severo, } \\
\text { que entendió la ruindad, } \\
\text { dijo: «Ista libertas hunc } \\
\text { hominem exitio dabit». }\end{array}$ \\
\hline
\end{tabular}

* [Nota al margen]: Sileno fue ayo de Baco, hombre juglar y burlador. 
Las diferencias de ambas versiones se deben en primer lugar a lo diverso del texto de partida, griego en un caso (si es que hemos de creer las aseveraciones de Diego Gracián) y latino en otro. No obstante, se aprecia que Gracián presenta un texto castellano amplificado, en el cual la presencia de parejas cuasisinónimas es mucho más abundante que en los Coloquios, con 9 casos («envidia y pesar», «mal hecha y afeada», «me pesa y me ensaño», «lisonjeros y hombres truhanes», "prendió y ató», «ni disimular ni callar», «estuviesen atentos y le prestasen atención», «oyese y escuchase», «destrucción y muerte»), por sólo uno en la obra de Arce («don y merced») $)^{31}$.

Los fragmentos insertados en latín obedecen a un rasgo típico de la poética de Arce de Otálora, que desde el prólogo de la obra justificó el engastado de ambas lenguas como un método de ampliación del público receptor. El latín no está utilizado para segregar un tipo de lector, sino para abarcar a los lectores de romance y a los latinos, asegurando que el mensaje sea accesible a los primeros y atorgando a los segundos un plus de comprensión lectora. En este fragmento, prácticamente bilingüe, el latín muestra claramente que la fuente seguida es el texto de Erasmo, al que se le practican algunos ajustes gramaticales y que muestra también errores de copia.

\section{Conclusión}

Todo el tratado plutarqueo está enfocado hacia el papel que la crítica ejerce en la amistad y las derivaciones éticas que se plantean al ejercerla. Qué debe y puede decir el amigo, qué hace y dice el adulador, y cuándo y cómo podemos discernir entre uno y otro, éstas son las preocupaciones de Plutarco. Al situar esta explicación (pues es Pinciano quien actúa como portavoz de la tesis) en un lugar estratégico, en el que se va gestando estructuralmente el cierre la obra, se nos invita a revisar la propia mecánica del discurso crítico. Quien critica es el amigo, y la crítica se realiza cuando el otro se aparta de la virtud. ${ }^{32}$ El adulador jamás actúa movido por la virtud, sino que dirá lo que el amigo quiere oír, exaltará sus vicios y, si critica, lo hará de forma débil y sobre aspectos poco importantes, para ganarse fama de franco y sincero. Que estos avisos morales permiten una lectura política en los Coloquios de Palatino y Pinciano nos parece claro, pues, como ya hemos advertido, estos globalmente expresan «un desengaño acerca de las estructuras sociales y culturales de la España del s. XvI» ${ }^{33}$.

Arce, que en el prólogo se había mostrado escrupuloso acerca del juicio de los demás y del efecto que sus burlas podrían causar en los lectores, se responde

31. Aun siendo la amplificatio un elemento esencial de estilo en los Coloquios. Ver al respecto Ocasar (2008: 85-90).

32. En esto Plutarco coincide con Cicerón, De Amicitia, 35, 44, etc.

33. Ocasar (2008: 263). 
a sí mismo en la Carta que «quien todo le leyere con atención y sin pasión, verá que va todo él enderezado a formar un hombre en buenas costumbres y cristiandad, y no se enseña ni pone en él, aun en las burlas, cosa que llegue a pecado venial, antes toda virtud y devoción» (24). Es el amigo el que afirma esa «ley de amistad»: que el amigo critica desde la virtud y que Arce, que se había mostrado amigo de todos, critica a todos.

La función textual de la amistad en los Coloquios de Palatino y Pinciano se nos revela ahora como fundamental. Su papel en la génesis, los usos sociales que le sirven de referente y la importancia como tema que adquiere a lo largo del viaje son derivaciones de una presencia más amplia aun. En efecto, si, como recordamos, la obra se dirige a todos los universitarios, entendidos como una gran e imprecisa sodalitas y si la amicitia es el sitio del amor crítico, entonces la obra completa se yergue como una especie de homenaje a una amistad vivida y proyectada. La crítica en ocasiones demoledora que Arce plantea al sistema de conocimiento no conduce, en última instancia, a la desesperación. La deriva optimista que evita que los Coloquios se conviertan en una obra negra o desesperanzada se fundamenta en un fuerte sentimiento de amistad vitalista y no idealizada, que se proyecta en la figura de un interlocutor concreto, pero también en una forma expandida que podríamos llamar sociabilidad, "que es uno de los bienes de naturaleza y consolaciones de la vida ${ }^{34}$. Dentro de esta amistad entendida como valor constitutivo de la sociedad es donde la crítica se hace pertinente y formativa, tanto del que la formula como del que la recibe. $Y$ es en este contexto en el que el opúsculo de Plutarco genera un nuevo testimonio del quehacer del humanismo (la traducción y mediación entre la cultura clásica y la coetánea), así como otro episodio más de la muchas veces oculta presencia de Erasmo en nuestras letras.

34. Coloquios, 891. 


\section{Bibliografía}

Arce de Otálora, Juan, Coloquios de Palatino y Pinciano, (2 vols.), Madrid, Turner, Biblioteca Castro, 1995.

Aresi, Paolo, Arte di predicar bene, nella quale, oltre a'precetti dè rètori à questo proposito applicati, si danno nuove regole, per tesser' ordinatamente una predi$c a$, per arrichirla di concetti, per ispiegarla convenevolemente, e per recitarla con decoro. Venice: Appresso Bernardo Giunti, Gio. Battista Ciotti, \& Compagni, 1611, pgs. 653-654.

Burke, Peter, The Art of Conversation, Ithaca, New York, Cornell University Press, 1993.

Chomarat, J., Grammaire et Rhetorique chez Erasme, Paris, Les Belles Lettres, 1981.

Goldsmith, Elizabeth, "Exclusive conversations»: the art of interaction in Seventeenth Century France, Philadelphia, University of Pensilvania Press, 1988.

Fumaroli, Marc, «La conversation», en Trois institutions littéraires, Paris, Gallimard, 1994.

Godo, Emmanuel, Histoire de la conversation, Paris, Presses Universitaires de France, 2003.

GrÉsILlON, Almuth, “"Nous avançons toujours sur des sables mouvants”. Espaces et frontières de la critique génétique», en Paul Gifford, Marion Schmid, La création en acte. Devenir de la critique génétique, Amsterdam-Nueva York, Rodopi, 2007.

Hankins, James (2009) Forthcoming. «Humanist academies and the "Platonic Academy of Florence.» In Proceedings of the conference, "From the Roman Academy to the Danish Academy in Rome,» ed. H. Ragn Jensen and M. Pade. Analecta Romana Instituti Danici Supplementum. Copenhagen: Odense University Press, 13-3-2014. http://dash.harvard.edu/handle/1/2936369

Henry, Patrick, Montaigne in Dialogue. Censorship and defensive writing; Architecture and friendship; The self and the other, Sartoga, Stanford University, Anma Libri, 1987.

Hyatte, Reginald, The Arts of Friendship. The idealization of friendship in Medieval and Early Renaissance Literature, Leiden, New York, Köln, E. J. Brill, 1994.

Kristeller, P. O., «Thomas More as a Renaissance Humanist», Moreana 65-6 (1980) pgs. 5-22.

JimÉnez San Cristóbal, Ana Isabel, «La noción de amistad en el De adulatore et amico de Plutarco", Cuadernos de Filología Clásica, 11, 2001, pgs. 255-278.

Jardine, Lisa, Erasmus, Man of Letters: The Construction of Charisma in Print, Princeton, Princeton University Press, 1993.

Mandrou, Robert, Des humanistes aux hommes de science, París, Éditions du Seuil, 1973; uso la edición en inglés, From Humanism to Sciencie 14801700, Suffolk, Penguin, 1978. 
Michel, Alain, «Linfluence du dialogue ciceronien sur la tradition philosophique et littéraire» en M.T. Jones-Davies, Le dialogue au temps de la Renaissance, Paris, Jean Touzot (Centre de recherches sur la Rennaissance, 9), 1984; pgs. 9-23.

Míguez, Roberto Augusto, «La influencia de la tradición clásica en la reflexión de Plutarco sobre la amistad», Montserrat Jufresa Muñoz (coord.), Plutarc a la seva época, paideia i societat: Actas del VIII Simposio Español sobre Plutarco, Barcelona, Sociedad Española de Plutarquistas, 2005; 25-2-2013 http://www.robertoaugusto.com/articulos/La_influencia_de_la_tradicion_ clasica_en_la_reflexion_de_Plutarco_sobre_la_amistad.pdf

Morales Ortiz, Alicia, Plutarco en España: traducciones de Moralia en el siglo XVI, Murcia, Universidad de Murcia, 2000.

Ocasar, José Luis, La lucha invisible. Estudio genético-literario de los Coloquios de Palatino y Pinciano, de Juan Arce de Otálora, Valladolid, Universidad de Valladolid, 2008.

-, Edición e Introducción a Coloquios de Palatino y Pinciano, de Juan de Arce de Otálora (2 vols.), Madrid, Turner, Biblioteca Castro, 1995.

—, "Un humanista del s. XVI: Juan Arce de Otálora», en Humanismo y Císter. Actas del I Congreso Nacional de Humanistas Españoles. León, Universidad de León, 1996; pgs. 379-387.

Morales de Plutarco; traduzidos de lengua griega en castellana [por Diego Gracián de Alderete], Alcalá, Juan de Brócar, 1548. http://hdl.handle.net/10481/11839

ÓsCar BIZARri, Hugo, "Non omnis moriar: sobre la fama del sabio en la Edad Media castellana», Thesaurus, XLV, no 1 (1990), pgs. 174-179.

Paterson, Annabel, Censorship and Interpretation. The conditions of Writing and Reading in Early Modern England, Madison, University of Wisconsin Press, 1984.

Rubiera, Javier, Para entender el cómico artificio. Terencio, Donato-Evancio y la traducción de Pedro Simón Abril (1577), Vigo, Academia del Hispanismo, 2009.

Strosetzki, Christoph, Rhétorique de la conversation: sa dimension littéraire et linguistique dans la société française du XVIIe siècle, París, 1984.

VAlléE, Jean-François, «The fellowship of the book: Printed Voices and Written Friendship in More's Utopia», en Dorothea Heitsch and Jean-François Vallée, Printed Voices. The Renaissance Culture of Dialogue, Toronto, Buffalo, London, University of Toronto Press, 2004, pp. 42-62.

Zugaza, Miguel, «Propaganda y mecenazgo literario: la familia de los Pizarros, Tirso de Molina y Vélez de Guevara», en Teatro, historia y sociedad. Seminario Internacional sobre Teatro Español y Novohispano del Siglo de Oro, ed. C. Hernández Valcárcel, Murcia, Universidad de Murcia-Universidad Autónoma de Ciudad Juárez, 1996, pp. 35-52. 